\title{
Comparative study on the efficacy of peritoneal dialysis and hemodialysis in patients with end-stage diabetic nephropathy
}

\author{
Xiao-dong Xu' ${ }^{1}$ Xue Han'2, Yi Yang ${ }^{3}, \mathrm{Xu} \mathrm{Li}{ }^{4}$
}

\begin{abstract}
Objective: Diabetic nephropathy is a serious threat to human health, and its incidence is on the rise. End-stage diabetic nephropathy (ESDN) requires extra investigation due to its complexity and severity, as well as serious concurrent diseases. Our objective was to compare the efficacy of hemodialysis (HD) and peritoneal dialysis (PD) in the treatment of ESDN.

Methods: Clinical data of 84 patients with ESDN admitted to our hospital from June 2016 to June 2018 were retrospectively analyzed. The patients were divided into an HD group that received hemodialysis and a PD group that received peritoneal dialysis. Their general conditions, biochemical indicators, residual renal function and incidence of complications were recorded and compared between the two groups.

Results: (1) No significant difference in diastolic blood pressure, systolic blood pressure, body weight, or urine output was detected between the two groups at the beginning of dialysis $(P>0.05)$. (2) Compared to the PD group, the HD group had significantly lower total cholesterol (TC) and triglyceride (TG) $(P<0.05)$, and significantly higher total protein (TP) and albumin (ALB) after treatment $(P<0.05)$. (3) The two groups also showed significant difference in residual renal function after treatment $(P<0.05)$. (4) The HD group had significantly higher systolic pressure than the PD group after treatment $(P<0.05)$. And more cases of infection were observed in the PD group than the HD group $(P<0.05)$.

Conclusion: Both HD and PD are used for treatment of ESDN, and can achieve similar calcium and phosphorus control. Compared to HD, PD has less adverse effect on hemodynamics and better preserves residual renal function, but is more likely to cause malnutrition and disorders of lipid metabolism. Therefore, choice of dialysis method should be based on specific conditions of each patient.
\end{abstract}

KEYWORDS: End-stage diabetic nephropathy, Hemodialysis, Peritoneal dialysis.

doi: https://doi.org/10.12669/pjms.36.7.2901

How to cite this:

Xu XD, Han X, Yang Y, Li X. Comparative study on the efficacy of peritoneal dialysis and hemodialysis in patients with end-stage diabetic nephropathy. Pak J Med Sci. 2020;36(7):1484-1489. doi: https://doi.org/10.12669/pjms.36.7.2901

This is an Open Access article distributed under the terms of the Creative Commons Attribution License (http://creativecommons.org/licenses/by/3.0), which permits unrestricted use, distribution, and reproduction in any medium, provided the original work is properly cited.

1. Xiao-dong $\mathrm{Xu}$,

2. Xue Han,

3. Yi Yang,

4. $\mathrm{Xu} \mathrm{Li}$,

Dean's Office, Cangzhou Medical College,

Hebei 061000 , P. R. China.

1-3: Department of Medicine,

Cangzhou Medical College,

Hebei 061000, P. R. China.

Correspondence:

$\mathrm{Xu} \mathrm{Li}$,

Dean's Office, Cangzhou Medical College,

Hebei 061000, P. R. China

Email: yismqy@sina.com

* Received for Publication:

* Accepted for Publication: *

May 14, 2020

August 22, 2020

\section{INTRODUCTION}

The incidence of diabetes is increasing year by year. ${ }^{1}$ Diabetic nephropathy is a common complication of diabetes, which seriously threatens human health. ${ }^{2}$ End-stage diabetic nephropathy (ESDN) is more troublesome and often complicated with serious comorbidities, making the treatment more difficult. ${ }^{3}$ Current treatment for ESDN mainly includes hemodialysis (HD), peritoneal dialysis (PD) and kidney transplantation. ${ }^{4}$ Although it has been shown that kidney transplantation has superior 
efficacy than PD and HD, the latter two remained the mainstream as only a small portion of patients had the chance to get kidney transplantation due to its high cost, limited kidney source, and requirements on patients' physical conditions. ${ }^{5}$ With the advancement of dialysis technology, it is still controversial which renal replacement therapy is the best choice for DN patients. ${ }^{6}$

For patients with ESDN, PD has less adverse effect on hemodynamics and is less traumatic, but it may increase glucose absorption, cause obesity and lipid metabolism disorders and more protein loss, and consequently malnutrition. In addition, for patients on peritoneal dialysis, ultrafiltration volume should be carefully controlled, changes in peritoneal permeability and the occurrence of peritoneal fibrosis should be noticed. On the other hand, for patients on hemodialysis, establishment of vascular access may take great effort and the risk of low blood pressure during treatment should be carefully addressed. Therefore, choice of dialysis method for ESDN patients remains to be studied. In this study, clinical data of 84 cases of ESDN on dialysis from June 2016 to June 2018 were retrospectively analyzed. Clinical efficacy and commodities were compared between patients receiving hemodialysis and those receiving peritoneal dialysis, so as to make a better choice of treatment for patients with ESDN and improve their prognosis.

A total of 84 patients with ESDN admitted to our hospital from June 2016 to June 2018 were included in this study for retrospective analysis. The sample size was determined by calculations with the PASS software.

\section{Inclusion criteria:}

1. ESDN patients with no history of hemodialysis or peritoneal dialysis before the study and aged 18 years or older.

2. Had maintenance dialysis (hemodialysis or peritoneal dialysis) for at least 3 years.

\section{Exclusion criteria:}

1. Renal failure caused by acute kidney injury.

2. Not ESDN.

3. Receiving both hemodialysis and peritoneal dialysis.

Ethical approval: This study was approved by the institutional ethics committee of XX Hospital (ethics number: 2016001), and written informed consent was obtained from all participants.

\section{METHODS}

The patients were divided into an HD group that received hemodialysis and a PD group that received peritoneal dialysis. The HD group included 44 cases (26 males and 18 females); had an average age of $58.4 \pm 6.3$ years (46-75); and were on dialysis for an average of $12.79 \pm 4.07$ months. The PD group included 40 cases (24 males and 16 females); had an average age of $57.4 \pm 7.7$ years (48-74); and were on dialysis for an average of $12.74 \pm 4.17$ months The two groups of patients were comparable, with no significant difference in gender, age, course of disease and residual renal function before treatment (Table-I).

Treatment: Before dialysis, the patients were treated as needed to control blood glucose and blood pressure, and to correct anemia and calciumphosphorus imbalance.

For hemodialysis, catheter to the central vein or arteriovenous fistula was used for vascular access, bicarbonate/reverse osmosis water solution was used as dialysate, and blood flow rate was set at 200-250 ml / minutes. And patients of the HD group received three hemodialyses a week, four hours each time. Patients in the PD group received peritoneal dialysis with the Y-type dialyzer (Baxter, U.S.) and dialysate containing 1.5\%-4.25\% sugar, 4 times a day, 2L each time.

Indicators of interest: General conditions (including body weight, urine output and blood pressure), laboratory indicators (including blood urea nitrogen (BUN), creatinine (Scr), parathyroid hormone (PTH), blood calcium $\left(\mathrm{Ca}^{2+}\right)$, blood phosphorus $(\mathrm{P} 3+)$, hemoglobin $(\mathrm{Hb})$, total protein (TP), albumin (ALB), triglyceride (TG), total cholesterol (TC), blood glucose, and residue renal function), as well as complications (including cardio-cerebrovascular diseases, bleeding, infection, malnutrition, arrhythmia, heart failure) of the two groups of patients were observed and recorded before and after dialysis.

Statistical analysis: SPSS20.0 statistical software was used for data procession and analysis.

Table-I: General conditions of the two groups.

\begin{tabular}{lcc}
\hline Variables & HD group & PD group \\
\hline Gender & & \\
Male & 26 & 24 \\
Female & 18 & 16 \\
Age (years) & $58.4 \pm 6.3$ & $57.4 \pm 7.7$ \\
Length of time on dialysis & $12.79 \pm 4.07$ & $12.74 \pm 4.17$ \\
GFR $\left(\mathrm{ml} / \mathrm{min} / 1.73 \mathrm{~m}^{2}\right)$ & $8.23 \pm 0.95$ & $8.21 \pm 0.97$ \\
\hline
\end{tabular}


Treatment in patients with end-stage diabetic

Table-II: Body weight, urine output and blood pressure of the two groups of patients.

\begin{tabular}{lcccc}
\hline Variables & \multicolumn{2}{c}{ At the start of dialysis } & \multicolumn{2}{c}{ After a year of dialysis } \\
\cline { 2 - 5 } & HD group & PD group & HD group & PD group \\
\hline Body weight $(\mathrm{kg})$ & $60.2 \pm 5.9$ & $62.6 \pm 6.1$ & $58.2 \pm 5.8$ & $60.2 \pm 5.7$ \\
Urine volume $(\mathrm{ml})$ & $935.5 \pm 133.6$ & $1040.5 \pm 203.6$ & $357.5 \pm 115.6$ & $655.1 \pm 148.6^{*}$ \\
Systolic blood pressure $(\mathrm{mmHg})$ & $161 \pm 15.2$ & $158 \pm 15.7$ & $156.3 \pm 14.8$ & $143.1 \pm 14.9^{*}$ \\
Diastolic blood pressure $(\mathrm{mmHg})$ & $85.3 \pm 8.4$ & $82.1 \pm 9.6$ & $79.5 \pm 7.8$ & $77.4 \pm 8.1$ \\
\hline
\end{tabular}

${ }^{*} \mathrm{p}<0.05$ for comparison between the two groups after a year of dialysis.

Measurement data were represented as mean \pm standard deviation $(x \pm s)$, and $t$ test was used for comparison between the two groups; count data were represented as percentage (\%), and compared with $\mathrm{X}^{2}$ test. $\mathrm{P}<0.05$ was considered statistically significant.

\section{RESULTS}

Before dialysis, no significant difference in body weight, urine volume, diastolic blood pressure or systolic blood pressure was observed between the two groups( $P>0.05)$, but significant differences in urine volume and systolic blood pressure were observed between the two groups after dialysis. Table-II.

After dialysis, the PD group had higher TC and TG levels $(\mathrm{P}<0.05)$, and lower TP and ALB levels than the HD group $(\mathrm{P}<0.05)$. Blood $\mathrm{Ca}^{2+}$ increased and $\mathrm{P} 3+$ decreased in both groups after treatment, but neither showed significant difference between the two groups at a year of dialysis. Table-III.

Changes of residual renal function of the two groups:

After dialysis, Src, BUN, and PTH decreased in both groups, but showed no significant difference between the two groups ( $>>0.05)$. After a year of dialysis, the PD group had significantly higher GFR than the HD group $(6.59 \pm 0.61$ vs. $7.42 \pm 0.81$ $\mathrm{ml} / \mathrm{min}$ ), indicating better preserve of residual renal function in the PD group. Table-IV.

After a year of dialysis, more cases of concomitant hypertension were observed in the HD group than the PD group $(\mathrm{P}<0.05)$. But the PD group had significantly higher rate of infections than the HD group (mostly peritonitis, 14/40 vs. 3/44, P<0.05). Table-V.

\section{DISCUSSION}

Diabetic nephropathy is a serious complication of diabetes, and is characterized by high incidence and poor prognosis, representing an important cause of death in patients with diabetes. ${ }^{7}$ Diabetic nephropathy has become a major cause of endstage renal disease. At the end stage of $\mathrm{DN}$, patients often develop serious complications. Accurate and timely diagnosis, and prompt treatment is the key to satisfactory prognosis. Renal replacement therapies are currently the major treatment for ESDN. Both HD and PD can significantly extend survival of patients with ESDN, and a lot of studies have compared the efficacy and incidence of complications between HD and PD. In the early stages of dialysis, peritoneal dialysis can achieve better efficacy than hemodialysis, but hemodialysis tends to result in higher survival rate than peritoneal dialysis among ESDN patients.

Table-III: Changes in the main laboratory indicators of the two groups.

\begin{tabular}{lcccc}
\hline Variables & \multicolumn{2}{c}{ HD group } & \multicolumn{2}{c}{ PD group } \\
\cline { 2 - 5 } & $\begin{array}{c}\text { At the start } \\
\text { of dialysis }\end{array}$ & $\begin{array}{c}\text { After a year } \\
\text { of dialysis }\end{array}$ & $\begin{array}{c}\text { At the start } \\
\text { of dialysis }\end{array}$ & $\begin{array}{c}\text { After a year } \\
\text { of dialysis }\end{array}$ \\
\hline Albumin (g/L) & $27.1 \pm 2.39$ & $31.9 \pm 2.14$ & $27.3 \pm 2.57$ & $28.7 \pm 1.91^{*}$ \\
Total protein (g/L) & $47.3 \pm 2.37$ & $55.3 \pm 2.29$ & $48.3 \pm 2.21$ & $50.3 \pm 1.76^{*}$ \\
Hemoglobin (g/L) & $82.3 \pm 5.81$ & $96.6 \pm 5.56$ & $83.2 \pm 5.88$ & $96.9 \pm 5.61$ \\
Total cholesterol (mmol/L) & $5.91 \pm 0.22$ & $5.96 \pm 0.19$ & $5.92 \pm 0.21$ & $6.36 \pm 0.29^{*}$ \\
Triglyceride (mmol/L) & $2.11 \pm 0.17$ & $2.06 \pm 0.16$ & $2.09 \pm 0.17$ & $2.20 \pm 0.18^{*}$ \\
Blood Ca2+ (mmol/L) & $1.78 \pm 0.13$ & $2.03 \pm 0.09$ & $1.85 \pm 0.11$ & $2.04 \pm 0.08$ \\
Blood P3+ (mmol/L) & $2.05 \pm 0.12$ & $1.89 \pm 0.09$ & $2.01 \pm 0.11$ & $1.84 \pm 0.10$ \\
Blood glucose (mmol/L) & $9.95 \pm 1.23$ & $7.66 \pm 0.83$ & $9.36 \pm 2.09$ & $7.8 \pm 0.87$ \\
\hline
\end{tabular}

${ }^{*} \mathrm{p}<0.05$ for comparison between the two groups after a year of dialysis. 
Xiao-dong Xu et al.

Table-IV: Changes of residual renal function of the two groups.

\begin{tabular}{lcccc}
\hline Variables & \multicolumn{2}{c}{ HD group } & \multicolumn{2}{c}{ PD group } \\
\cline { 2 - 5 } & $\begin{array}{c}\text { At the start } \\
\text { of dialysis }\end{array}$ & $\begin{array}{c}\text { After a year } \\
\text { of dialysis }\end{array}$ & $\begin{array}{c}\text { At the start } \\
\text { of dialysis }\end{array}$ & $\begin{array}{c}\text { After a year } \\
\text { of dialysis }\end{array}$ \\
\hline Blood creatinine $(\mathrm{umol} / \mathrm{L})$ & $781.5 \pm 172.9$ & $621.6 \pm 86.1^{*}$ & $791.2 \pm 193.2$ & $680.2 \pm 95.7$ \\
Blood urea nitrogen $(\mathrm{mmol} / \mathrm{L})$ & $21.5 \pm 3.6$ & $18.0 \pm 3.2^{*}$ & $21.5 \pm 3.9$ & $18.1 \pm 3.7^{*}$ \\
PTH $(\mathrm{pg} / \mathrm{ml})$ & $261 \pm 87.2$ & $209.1 \pm 65.7^{*}$ & $245.3 \pm 84.2$ & $213.1 \pm 64.9^{*}$ \\
GFR $\left(\mathrm{ml} / \mathrm{min} / 1.73 \mathrm{~m}^{2}\right)$ & $8.23 \pm 0.95$ & $6.59 \pm 0.61$ & $8.21 \pm 0.97$ & $7.42 \pm 0.81 \#$ \\
\hline
\end{tabular}

${ }^{*} \mathrm{p}<0.05$ for comparisons between data of the same group before and after a year of dialysis

\# $\mathrm{p}<0.05$ for comparisons between the two groups after a year of dialysis.

Table-V: Incidence of adverse reactions of the two groups.

\begin{tabular}{lcccc}
\hline Adverse reactions & \multicolumn{2}{c}{ HD group $(n=44)$} & PD group $(n=40)$ \\
\cline { 2 - 5 } & $\begin{array}{c}\text { At the start } \\
\text { of dialysis }\end{array}$ & $\begin{array}{c}\text { After a year } \\
\text { of dialysis }\end{array}$ & $\begin{array}{c}\text { At the start } \\
\text { of dialysis }\end{array}$ & $\begin{array}{c}\text { After a year } \\
\text { of dialysis }\end{array}$ \\
\hline Hypertension & 40 & 32 & 36 & $20^{*}$ \\
Arrhythmia & 6 & 8 & 6 & 4 \\
Heart failure & 10 & 6 & 8 & 4 \\
Infection & 10 & 3 & 12 & $14^{*}$ \\
\hline
\end{tabular}

${ }^{*} \mathrm{p}<0.05$ for comparison between the two groups after a year of dialysis.

Hemodialysis can quickly remove toxins from the body, thus improve symptoms such as nausea and vomiting, reduce edema and improve appetite. ${ }^{8}$ While peritoneal dialysis is more continuous and stable, resulting in higher quality of life - intake of water and salt depends on daily clearance, which avoids water-sodium retention and maintains a relative balance of the body. For both groups, dialysis relieved the discomfort symptoms, improved appetite, reduced endotoxin levels, and corrected calcium and phosphorus metabolism disorders, so both HD and PD are effective treatment for patients with ESDN. ${ }^{9}$

It was observed in this study, urine volume significantly decreased in the HD group, but was largely maintained in the PD group, suggesting that PD may better preserve residual renal function than HD. PD also had less adverse effect on hemodynamics than HD, the possible causes may include no need to establish arteriovenous fistula; more stable PD and electrolyte balance; continuous and stable toxin removal; no significant changes in heart filling, myocardial contraction or oxygen demand during and between dialyses; better control of blood pressure; and better preserve of residual renal function. Hemodialysis has significant influence on circulatory dynamics, and use of anticoagulants during hemodialysis often leads to complications such as disequilibrium syndrome, and cardiovascular and cerebrovascular diseases. ${ }^{10,11}$ Blood pressure of the HD group was not well controlled, even after administration of antihypertensive drug for some patients. The causes may include water-sodium retention, insufficient ultrafiltration, increased vagal tone, and HD-related drug absorption and poor dialysis clearance.

Malnutrition and dyslipidemia are more commonly observed in patients on PD than those on HD. ${ }^{12,13}$ In this study, the lower total protein and albumin levels in the PD group appear to be related to higher level of protein loss. and the decreased cholesterol and triglyceride levels may be caused by increased glucose intake associated with PD, and increased synthesis of these lipids in the liver in response to hypoproteinemia. In recent years, the introduction of novel dialysates has somewhat reduced PD-related lipid metabolism and nutritional disorders. Some studies have shown that dialysate supplemented with amino acids and glucose at a certain ratio can provide protein and energy needed by the body, which is particularly useful for patients with insufficient food intake. ${ }^{14}$

The incidence of PD-related peritonitis also significantly decreased with technological advances. ${ }^{15}$ Infections were more common in the PD group than the HD group, which may be caused by weakened immunity due to significant protein loss. ${ }^{16}$ Therefore, patients on PD should 
pay more attention on diet, taking appropriate amount of high-quality protein and foods rich in vitamins and cellulose, and prevent diarrhea through food hygiene. In addition, peritoneal dialysis patients should be promptly followed up, with special attention on residual renal function as well as prevention and treatment of complications. ${ }^{17}$

At present, choices for the method and timing of dialysis are the major problems when treating patients with ESDN, and there are different views about them. ${ }^{18}$ For timing of dialysis, the US NKF-K/DOQI pointed out that dialysis for ESDM patients should be started when there is significant deficiency in renal function. It has been recommended that patients with SCR $>442 \mathrm{umol} / \mathrm{L}$ and $\mathrm{CCR}<15 \mathrm{ml} / \mathrm{min}$ should receive dialysis, and for those with early occurrence of uremia, dialysis should be started even earlier, as soon as CCR reduced to below $20 \mathrm{ml} /$ minutes. Survival of ESDN patients on PD is closely related to residual renal function at the start of dialysis, nutritional status and comorbidities. ${ }^{19}$ So, timing of dialysis should be chosen based on comprehensive consideration of the patient's kidney function, nutritional status and complications. In clinical practice, choice of dialysis method should also be made based on comprehensive evaluation of patient's specific conditions, such as age, economic status, family environment and medical conditions, condition of the blood vessels, history of abdominal surgeries, general conditions, and major comorbidities before dialysis, etc. For patients with severe edema, hyperkalemia, or those who can't have PH due to a history of abdominal surgeries, HD should be the choice. And for those who live in remote areas, have poor vascular conditions for establishment of vascular access, or have severe cardiovascular and cerebrovascular diseases, peritoneal dialysis should be the choice. Elderly patients with ESDN may choose PD at first to better preserve residual renal function, then switch to HD as needed.

Therefore, patients with ESDN should start dialysis as early as possible and chose the dialysis method most appropriate for each patient, which may change as the disease progresses. In addition, sufficient attention should be paid to control of blood sugar, blood lipids, and blood pressure, to improve nutritional status of patients, and to prevent various complications, so as to improve survival rate and quality of life of the patient.
Limitations of the study: This study is limited by its retrospective nature: prospective randomized controlled studies should be performed in the future. And prognosis of ESDN patients on the two types of dialysis and relevant risk and protective factors should be further investigated.

\section{CONCLUSION}

Both HD and PD are used for treatment of ESDN, and can achieve similar calcium and phosphorus control. HD showed better efficacy than PD in improving serum total protein and albumin. PD can better preserve residual renal function of patients with ESDN, but it tends to cause dyslipidemia. Patients with ESDN should start renal replacement therapy as early as possible, and the choice of dialysis method should be personalized and adjusted over time.

\section{Declaration of interest: None.}

Source of funding: None.

\section{REFERENCES}

1. Selby NM, Taal MW. An updated overview of diabetic nephropathy: Diagnosis, prognosis, treatment goals and latest guidelines. Diabetes Obes Metab. 2020;22(Suppl1):3-15. doi: 10.1111/dom.14007

2. Stephens JW, Brown KE, Min T. Chronic kidney disease in type 2 diabetes: Implications for managing glycaemic control, cardiovascular and renal risk. Diabetes Obes Metab. 2020;22 (Suppl1):32-45. doi: 10.1111/dom.13942

3. Jin YP, Su XF, Yin GP, Xu XH, Lou JZ, Chen JJ, et al. Blood glucose fluctuations in hemodialysis patients with end stage diabetic nephropathy. J Diabetes Complications. 2015;29(3):395-399. doi: 10.1016/j.jdiacomp.2014.12.015

4. Tyden G, Bolinder J, Solders G, Brattstrom C, Tibell A, Groth CG. Improved survival in patients with insulin-dependent diabetes mellitus and end-stage diabetic nephropathy 10 years after combined pancreas and kidney transplantation. Transplantation. 1999;67(5):645-648. doi: 10.1097/00007890199903150-00001

5. Caldara R. Il trattamento della nefropatia diabetica con IRC [Treatment of end-stage diabetic nephropathy]. G Ital Nefrol. 2008;25(Suppl44):S64-S67.

6. Massoth C, Zarbock A. Organersatzverfahren: Update Nierenersatztherapie [Update: Renal Replacement Therapy]. Anasthesiol Intensivmed Notfallmed Schmerzther. 2020;55(3):178-189. doi: 10.1055/a-0853-3928

7. Ryan L, Brown E. Supporting and maintaining the frail patient on long-term renal replacement therapy. Clin Med (Lond). 2020;20(2):139-141. doi: 10.7861/clinmed.2019-0416

8. Kim SM, Kang BC, Kim HJ, Kyung MS, Oh HJ, Kim JH, et al. Comparison of hemodialysis and peritoneal dialysis patients' dietary behaviors. BMC Nephrol. 2020;21(1):91. doi: 10.1186/s12882-020-01744-6.

9. Choi SJ, Obi Y, Ko GJ, You AS, Eriguchi R, Wang M, et al. Comparing Patient Survival of Home Hemodialysis and Peritoneal Dialysis Patients. Am J Nephrol. 2020;51(3):192200. doi: $10.1159 / 000504691$ 
10. Tsujimoto H, Tsujimoto $\mathrm{Y}$, Nakata $\mathrm{Y}$, Fujii T, Takahashi $S$, Akazawa $M$, et al. Pharmacological interventions for preventing clotting of extracorporeal circuits during continuous renal replacement therapy. Cochrane Database Syst Rev. 2020;3(3):CD012467. doi: 10.1002/14651858. CD012467.pub2

11. Chang CH, Fan PC, Lin YS, Chen SW, Lin MS, Wu M, et al. Atrial fibrillation and associated outcomes in patients with peritoneal dialysis and hemodialysis: a 14-year nationwide population-based study. J Nephrol. 2020. doi:10.1007/ s40620-020-00713-4.

12. Kang GH, Kim YN, Shin HS. Relationship between geriatric nutritional risk index and subpopulation lymphocyte counts in patients undergoing hemodialysis and peritoneal dialysis. Ren Fail. 2016;38(10):1589-1593. doi: 10.3109/0886022X.2015.1128234

13. Naini AE, Karbalaie A, Abedini M, Askari G, Moeinzadeh F. Comparison of malnutrition in hemodialysis and peritoneal dialysis patients and its relationship with echocardiographic findings. J Res Med Sci. 2016;21:78. doi: 10.4103/17351995.189695

14. Mehrotra R. Nutritional issues in peritoneal dialysis patients: how do they differ from that of patients undergoing hemodialysis? J Ren Nutr. 2013;23(3):237-240. doi: 10.1053/j.jrn.2013.01.031

15. McGill RL, Weiner DE, Ruthazer R, Miskulin DC, Meyer $\mathrm{KB}$, Lacson E Jr. Transfers to Hemodialysis Among US Patients Initiating Renal Replacement Therapy With Peritoneal Dialysis. Am J Kidney Dis. 2019;74(5):620-628. doi: 10.1053/j.ajkd.2019.05.014

16. Simoes-Silva L, Araujo R, Pestana M, Soares-Silva I, Sampaio-Maia B. The microbiome in chronic kidney disease patients undergoing hemodialysis and peritoneal dialysis. Pharmacol Res. 2018;130:143-151. doi: 10.1016/j phrs.2018.02.011
17. Salame C, Eaton S, Grimble G, Davenport A. Protein Losses and Urea Nitrogen Underestimate Total Nitrogen Losses in Peritoneal Dialysis and Hemodialysis Patients. J Ren Nutr. 2018;28(5):317-323. doi: 10.1053/j.jrn.2018.01.016

18. Sola L, Levin NW, Johnson DW, Pecoits-Filho R, Aljubori HM, Chen Y, et al. Development of a framework for minimum and optimal safety and quality standards for hemodialysis and peritoneal dialysis. Kidney Int Suppl. 2020;10(1):e55-e62. doi: 10.1016/j.kisu.2019.11.009

19. Xue J, Li H, Zhou Q, Wen S, Zhou Q, Chen W. Comparison of peritoneal dialysis with hemodialysis on survival of diabetic patients with end-stage kidney disease: a metaanalysis of cohort studies. Ren Fail. 2019;41(1):521-531. doi: 10.1080/0886022X.2019.1625788

20. Subramanian L, Zhao J, Zee J, Knaus M, Fagerlin A, Perry E, et al. Use of a Decision Aid for Patients Considering Peritoneal Dialysis and In-Center Hemodialysis: A Randomized Controlled Trial. Am J Kidney Dis. 2019;74(3):351-360. doi: 10.1053/j.ajkd.2019.01.030

21. Kanda R, Io H, Nakata J, Makita Y, Sasaki Y, Matsumoto M, et al. Evaluation of Long-Term Combination Therapy With Peritoneal Dialysis and Hemodialysis. Ther Apher Dial. 2017;21(2):180-184. doi: 10.1111/1744-9987.12517

\section{Authors' Contributions:}

XDX and XL designed this study and prepared this manuscript, and are responsible and accountable for the accuracy or integrity of the work. XH collected and analyzed clinical data YY significantly revised this manuscript. 